\title{
Public Pedagogy Analysis in Coal-Rich Areas in Pakistan and China
}

\author{
Muhammad Azeem Ashraf, Iqra Ismat and Jelena Milenkovic
}

\begin{abstract}
This paper focuses on analyses of public education in coal rich areas in Pakistan and China. With modern development, energy has become world's largest need. Coal is very important to fulfil their need for energy but it pollutes the environment very badly and cause diseases. Governments use public pedagogy that includes the media and the internet, formal and informal sources of the media, to promote itself as an ecofriendly and people-caring. People who are using the coal as a business are becoming richer and richer, but the people who live in these areas (coal rich areas) are suffering from the environmental and health problems. People from these areas are not getting equal education facilities, proper environmental and health education. Governments in both counties are using coal to build economy at the expense of people's health and well-being.
\end{abstract}

Index Terms - Coal, environment, education, health, media, public pedagogy.

\section{INTRODUCTION}

With modern development, energy has become world's largest need. According to World Health Organization the most polluted cities in the world are Karachi, Pakistan; New Delhi, India; Beijing, China; Lima, Peru; and Cairo, Egypt (WHO, 2014) [1]. One of the biggest reasons for water and air pollution in China and Pakistan is the coal industry. Coal is very important to fulfil their need for energy and to make money but it pollutes the environment badly and causes diseases. According to the reports issued by the World Health Organization [2] in 2008 and by environmental groups in 2004, coal particulates pollution are estimated to shorten approximately 1,000,000 lives annually worldwide. Apart from causing diseases and polluting environment, coal mine industry is responsible for large number of workers deaths. Thousands of miners die from mining accidents each year, especially in the processes of coal mining and hard rock mining [3]. Most of the deaths nowadays occur in developing countries especially China and rural parts of developed countries. Those rural coal-rich parts of the country are usually economically poor; majority of population is living in bad conditions without proper health and environmental education. China is the world's largest coal consumer; it is also one of the largest producers of coal. Coal production rose $8.1 \%$ in 2006 , reaching 2.38 billion tons, and the nation's largest coal enterprises saw their

Manuscript received September 5, 2015; revised October 25, 2015. It is work done by authors during their master degree.

Muhammad Azeem Ashraf and Jelena Milenkovic are with Beijing Normal University, Beijing, China (e-mail: azeem20037@gmail.com, milenkovic_jelena@hotmail.com).

Iqra Ismat is with Bahauddin Zakariya University, Sahiwal Campus, Pakistan (e-mail: iqraismat@yahoo.com). profits exceed 67 billion Yuan, or $\$ 8.75$ billion. If we look into coal fields in Sindh, Pakistan, which has the largest coal fields in the country, environmental, and social problems are the same as in Shanxi. Pakistan's coal fields, which are the largest in the country, are located in TharParkar district, one of the 23 districts in Sindh province. The people in the TharParkar district (including urban and rural areas) are living with lack of education, environmental protection and social facilities and this is even worse in rural areas. The provincial government is busy with inviting domestic and international companies to invest in these coal fields, but pays very little attention to the rights of local people. In this case, very poor statistical data available of TharParkar district on government official websites.

Both Chinese and Pakistan's governments and coal mine owners are using coal for their benefit, but they don't pay a lot of attention to environmental and health issues in coal areas. Social injustice challenges this world to think over the environmental devastation. Public pedagogy has been used to manipulate most of the population while owners of coal mine companies are getting richer with increase influence of government. China and Pakistan have coal-rich areas, although this areas are rich in natural resources, economically speaking they are considered to be poor. In China the growing income inequality is illustrated most clearly by the differences in living standards between the urban, coastal areas and the rural, inland regions. There have also been increases in the inequality of health and education outcomes. Majority of population in these areas are not benefiting from natural resources and they are manipulated by public pedagogy, they often don't realize all the social injustice that has been done. In this paper we are going to look into how public pedagogy is being used in coal-rich areas in China and Pakistan. This paper is using Burdick \& Sandlin's [4] definition of public pedagogy (2010):

"The term public pedagogy first appeared in 1894 and has been widely deployed as a theoretical construct in education research to focus on processes and sites of education beyond formal schooling... Finding that the public pedagogy construct is often under theorized and ambiguously presented in education research literature, the study identifies five primary categories of extant public pedagogy research: (a) citizenship within and beyond schools, (b) popular culture and everyday life, (c) informal institutions and public spaces, (d) dominant cultural discourses, and (e) public intellectualism and social activism."

This paper focuses on two coal-rich areas, one in China (Shan Xi) and one in Pakistan (Sindh). The GDP per capita of Shanxi is below national average. Compared to the provinces in East China, Shanxi is economically less developed. Shanxi possesses 260 billion metric tons of known coal deposits, about one third of China's total 
(Economic News and Statistics for Shanxi's Economy, 2014) [5]. As a result, Shanxi is a leading producer of coal in China and has more coal companies than any other province, but Shanxi is infamous for bad working conditions, thousands of workers have died every year. Datong, city in north of Shanxi province claims one of biggest coal fields. The Datong Coal Mining Group [6] is based here and is China's third largest such enterprise. In contrast with the poverty, Datong is known for its wealthy mine owners in China. Sindh is located in southeast of Pakistan and has the second largest economy in Pakistan; in 2010 Its GDP per capita was $50 \%$ more than the rest of the nation or $35 \%$ more than the national average. With $23.7 \%$ of country's population, its contribution to the national GDP is around $30 \%$. And it is contributing $65-69 \%$ of national tax collection. According to the private power and infrastructure board's report (2004) [7] Sindh has the largest coal reserves in Pakistan with is approximately 184.623 billion tones. Having the largest coal reserves and second largest economy in Pakistan, doesn't help most people with their lives. People are having lack of education, money, and food in these areas. There is very poor statistical data available on the government official websites about the status of health, education, environment and economy in TharParkar district. Sindh Engro Coal Mining Company (A Joint Venture between Government of Sindh and Engro Corporation) [8] was formed to develop, construct and operate an open cast mine at Thar coalfield. According to our research through government websites, there are very few laws about the environmental protection, and no government has ever paid serious attention to the environmental issues in the province, especially in TharParkar.

Pollution, poor status of health and safety of the workers, lack of education and health status for the local people, are the common problems of both regions (i.e. Datong and TharParkar). Pollution is the most dominant problem in both regions because of politically unobstructed usage of coal and less attention to the environment. Access to education is another leading problem in both cities. Both regions have less number of schools and colleges than other part of countries, with poor facilities inside the schools. Poor status of health and safety for workers is another one of the biggest problems that these regions are facing. No clear data is available for the worker's health status and their safety. We argue in this paper that media is playing one-sided role in both cities; showing investments and profits of companies but have nothing on the status of lives of local people. Coal mine companies in both areas are proclaiming themself as an essential part of the community, by employing $\mathrm{X}$ number of workers, giving them and their families chance for "better future", organizing all kinds activities (social and environmental), all that while heavily polluting the environment.

\section{Public Pedagogy Analysis}

\section{A. China}

China is a communist country and Chinese Communist Party is responsible for censorship in China. Censored subjects include: Tiananmen Square protest in 1989,
Maoism, Falun Gong, ethnic independence movements, corruption, police brutality, anarchism, gossip, disparity of wealth, food safety, pornography, news sources that report on these issues, unregistered religious content, and many other websites, including Facebook and You Tube (Kenji, 2010)[9]. Censored media include: television, print media, radio, film, theatre, text messaging, literature and Internet. Everything that can hurt government's image is banned from media and access to foreign media is limited. To protect itself government will manipulate information or just deny access to it. Due to censorship it is not easy to access information, and for the one we can access reliability is in question. Environmental issues are present in today's China but information about it can be very different depending on its source, especially if it is coming from the government. In China, most of the coal mines are state owned. In this paper we will look into one of state owned coal mines web page and newspapers articles to see how public pedagogy has been used.

The third largest state-owned coal mine industry in China is Datong Coalmine Group. The Datong Coalmine Group Co Ltd is located 15 kilometers to the southwest of downtown Datong. It has a 1,827-square-kilometer coalmine area, 37.58 billion tons of reserves, and 15 large mines, with an annual total output of 34.5 million tons. Datong Coalmine Group has around 113,000 workers and it presents itself as an essential part of the community. On their website, beside, general information about company and its work, there are sections dedicated to company's charity work, environment and social involvement. In a section "Civilization" there is news about company's social involvement. We can see that Datong Coalmine Group is an important part of Datong community. "Coal Sea of Hope" is an initiative organizes by Datong Coalmine Group for children of workers who cannot afford to pay university tuition fee. On this occasion 104 students were granted 6000 RMB for tuition fees. "Rise up tomorrow's Sun" another initiative by this company to help education, this time they invested 3 million RMB to transform three kindergartens, by redecorating facilities and buying new equipment for kindergartens. Datong Coal Mine Group [6] won the title of Winning Unit in the national "Safety and Health Cup" competition, given by All-China Federation of Labor and State Administration of Work Safety [10] (governmental organization). Recently, Datong Coal Mine Group has centered on the theme of the national "Safety and Health Cup" competition and taken the staff's safe and health as the guideline to push on the safety culture construction, enhance the subunits' safety management, implement the grassroots' "Safety and Health Project" and promote a variety of activities, such as safety and health knowledge training, accidents and occupational hazards screening and governance, which creates "everybody cares for safety, everybody pays attention to safety" and promotes the enterprise's safety production in a continuous, healthy and steady development way. In section dedicated to environmental involvement company is presented like a "green" company: "Beautiful coalmine with beautiful scenery". Taking the ecological civilization as the leading of the enterprise's development, and by promoting greening projects, the comprehensive control of coal gangue piles, air 
pollution control projects and water comprehensive use projects, coalmine of Datong Coal Mine Group explored a low-carbon path to meet the enterprise's own development. All of the online text examples given, we have found that the online imaginary and its descriptions given by the company present an image of new modern coalmine, which is the flowers opening in three seasons, green in four seasons and has a neat and clean office environment. Just by looking their website we can deduce that Datong Coalmine Group is a green company who takes care of their workers, environment and community in general. But, things are not that simple. According to report issued by Ministry of Environmental Protection in November of 2013 Datong Coalmine Group is one of 72 companies that are put in blacklist as the biggest polluters in China. Datong Coalmine Group exploitation of coal resulted in water resource destruction $(32.5 \%$ of the total area is under a "highly vulnerable zone"), air pollution, landslide soil property changes and soil erosion aggravations (Qiu, Guo, \& Shuangguan, 2009) [11]. Apart from causing environmental problems, the Datong Coailmine Group is responsible for the deaths of miners. On 5 November 2006, a gas explosion at the Jiaojiazhai mine in Shanxi province, which was operated by Xuangang Coal and Power Company, a subsidiary of Datong coal mine Group, killed 47 miners. In 2008, 21 people died as a result of gas explosion in the mine. Whenever a mining accident with exceptional loss of life (more than 30 fatalities) occurs in China, the government-controlled media briefly report the cause and the number of victims, but focus more on the stirring rescue efforts and the government's post-accident management strategy. The state run media report the story almost exclusively from the government's perspective, and only occasionally is it possible to determine from these reports whether the families of the victims were satisfied with the government's efforts or the economic compensation they received. A government official in a coal mining area told the Workers' Daily [12] in 2002 that "after fatal accidents, mine operators frequently settle things by making a bereavement payment and reaching private agreements with the families. The sums range from 15,000 RMB to over $20,000 \mathrm{RMB}$. Some payments go up to $24,800 \mathrm{RMB}$, because 'two four eight' (in the local dialect) sounds like 'sent to the next world.

\section{B. Pakistan}

Pakistan is a moving towards democratic country with a history of military governments and poor democratic governments. Free media has been established in beginning of this century. That was a big change for Pakistan because that was first time for Pakistani nation and government (i.e., both military and democratic) to face the free media and in no time, it becomes challenge for government because of too much criticism by media on government's policies and politician's character. According to the Pakistan Media report 2009, [13] Pakistan has a vibrant media landscape; among the most dynamic in South Asia. To a large extent the media enjoys freedom of expression in spite of political pressure and direct bans sometimes administered by political stakeholders ( $p, 14)$. So in response to that, free media has faced many challenges from government including banning of TV channels, newspapers etc. The UK Foreign Office states that it is vital that the right to freedom of expression continues to be upheld by the Pakistani Government. Due to facing many challenges, media now have become more politically than public, like it pays more attention on the political system of the country and pays vey less attention on the public. Some areas in Pakistan suffer from a lack of access to information or only receive information that is one-sided and manipulated.

According to Thar Coal energy board website [14], The Thar coalfield with a resource potential of 175 billion tonnes of coal covers an area of over 9,000 sq. $\mathrm{km}$ in the Thar Desert in Thar Parkar district, in south eastern part of Sindh. The investigated area is covered by stable sand dunes and there are no rock exposures. Thar coalfield was divided into six blocks and two companies have been given license. Exploration licence was issued to Oracle Coalfields [15] in Nov. 2007. Sindh Engro Coal Mining Company (SECMC) [8] was formed as a result of Joint Venture Agreement between Government of Sindh and Engro Group (40\% Sindh Government; 60\% Engro) to develop, construct and operate an open cast mine at Block-II of Thar coalfield. The both companies are in contract with government of Sindh for the Thar coalfields. By looking into their annual reports, the first company is running in loss for the past two years, and the second company doesn't show its annual report of how much profit they are making or how much loss they are facing? But it shows that, both companies are paying no attention to the local population. And there is no data available about the public work. There is no news on their website or even on media that any event which these companies organized in Tharparkar district for the benefits of local people.

According to the MDG report [16] of 2012 by UN, the Caloric Poverty rate and dependency in Tharparkar district are $72.4 \%$ and $117.5 \%$ respectively, which is higher among all other districts in the province. The literacy rate of Tharparkar district (age 10+) is $46 \%$, with $45 \%$ rural and $69 \%$ urban with big difference of male to female which is male $65 \%$ and female $25 \%$ only which is less than national and provincial level (National: 58\%, Provincial: 59\%). GPI (gender parity index) for Adult Literacy who are above fifteen years of age is 0.24 in Tharparkar. There are only $45 \%$ children of age 12-23 months are fully immunized in Tharparkar district and only $63 \%$ of age 12-23months children are immunized against Measles. Only $42 \%$ females have access to ante-natal facilities in district. The above statistical data shows the state of life of the people in Tharparkar district. The people of this district are still facing the challenges even they have biggest coal mines in the country, and government and coal companies are digging coal from their lands without improving their living conditions. According to the Thar Coal and Energy Board website, government has built new roads and ground breaking of Tharparkar airport and Thar Lodge for the investors and engineers who are working in the coal field. But there is no evidence of news or act from government for the people of that district. There is even no single project named for the local residents for improving their health, education or living standards by any of both companies. 


\section{COMPARISON BETWEEN CHINA AND PAKISTAN}

\section{A. Environmental Situation}

As we can see, both China and Pakistan are facing the same types of problem. Areas rich with natural resources, in this case coal rich areas, are one of the economically poorest areas, with high rates of illiteracy, limited access to hospitals and schools, and with huge environmental problems. The GDP per capita of Shanxi is below national average. Shanxi's nominal GDP in 2011 was 1110.0 billion RMB (US\$176.2 billion), ranked 21st in China. Its per-capita GDP was 21,544 RMB (US\$3,154). Industry in Shanxi is based on heavy industries such as coal and chemical production and power generation. Many private corporations, both Chinese and foreign, joint with the state-owned mining corporations have invested billions of dollars in the Mining Industry of Shanxi Province. Shanxi is known for its wealthy mine owners in China, but on average Shanxi province is considered poor. Shanxi is infamous for bad working conditions in coal mining and other heavy industries. Thousands of workers have died every year in those industries. State Administration of Work Safety reported that 5,986 coal miners died in 2005. In terms of education, Shanxi is also below national average. In 2000 illiteracy rate for Shanxi province was: $3.21 \%$ for male and $8.31 \%$ for female. Other provinces with higher GDP had lower rates like Beijing (2.02 for male and 8.1 for female 8.1 ) or Shanghai (2.35 for male and 8.1 for female. Average years of education in Shanxi are 8.70 for male and 8.03 for female (Beijing 10.29 for male, 9.60 for female). Dropout rate in Shanxi is 2.9 for male and 4.1 for female in comparison to Beijing 1.6 for male and 1.3 for female (World Bank, 2006) [17]. According to Economic News and Statistics for Shanxi's Economy [5], In the 2000s, the province was considered to be one of the most polluted areas in China.

The pollution has caused health problems in the province. In the first quarter of 2013, PM2.5 concentration levels of Shanxi province was more than two times the national standard, at 35 micrograms per cubic meter (Green Peace Asia, 2013) [18]. The rate of birth defects in this region is six times higher than the national average. In the U.S., for every 10,000 live births, there are 7.5 infants with neural tube defects. In Shanxi province, that number is 18 times higher: 140 infants. Over a 10-year period, the researchers gathered placentas from 80 stillborn or newborn infants in Shanxi with the disorder. Based on their analysis, they confirmed that those infants had been exposed in utero to significant levels of pesticides, industrial solvents, and especially polycyclic aromatic hydrocarbons (PAHs), which are released into the air when fossil fuels are burned (Ren, A., et al, 2011) [19]. China has promised to clear up its air and water, but in this province, industry comes before a cleaner environment.

Food and water is another very big problem of these two areas. Different studies show that the food and water from these areas are really toxic for human body. According to the report published by Research Center for EcoEnvironmental Sciences, Chinese Academy of Sciences, high percentages of water ( $77 \%$ of $n=131$ total samples), vegetables $(92 \%, n=120)$, cereals $(32 \%, n=25)$, urine
(70\%, $n=99)$, nails $(76 \%, n=176)$, and hair $(62 \%, n=61)$ contained arsenic (As) higher than the acceptable levels. And chronic exposure to arsenic (As) threatens human health. As concentration was less than $10 \mu \mathrm{g} / \mathrm{L}$, for which 5 out of 30 examined participants were diagnosed with arsenicosis symptoms. According to the report published in journal of applied sciences on Status of Water Bodies and their Effect on Human Health in District Tharparkar, Water samples were collected from representative water bodies. In all, 95 water samples were collected from Dug wells (79), Hand/Motor pumps (9), water supply schemes (4), Canal water (2) and Tanko (1). The analyzed samples were found contaminated with coliform bacteria, had higher TDS (total dissolved solids), $\mathrm{pH}, \mathrm{EC}$, hardness, alkalinity, iron and manganese and phosphate concentrations compared to the standard permissible limits.

Role of public pedagogy in education is grooving day by day, mainly thanks to the influence of the media. According to Giroux public pedagogy describes the nature of the spectacle and the new media, and the political and educational force of global culture. He sees educational force of culture like the way we understand world. Giroux [20] also argued that: "The media's overpowering influence in our lives and the fact that we never actually confront pristine reality (only a mediated version), raises the question: Could the cultural apparatus be the most influential teacher we ever have?"

This means that media's role in our life bigger that we would like to admit. Every day we rely on media to inform us or not to inform us (hide the information) and by doing that it also educate us. Media has become the fastest and the easiest way to get information and therefore it is essential in democratic society. Knowledge is the main catalyst behind political change; it can lead to political mobilization and, ultimately, regime change. Access to information is essential for democracy for many reasons: first, it ensures that citizens make responsible, informed choices rather than acting out of ignorance or misinformation. Second, information serves a "checking function" by ensuring that elected representatives uphold their oaths of office and carry out the wishes of those who elected them. Within the context of supporting democratic transitions, the goal of media development generally should be to move the media from one that is directed or even overtly controlled by government or private interests to one that is more open and has a degree of editorial independence that serves the public interest (Centre for Democracy and Governance, 1999) [21]. Unfortunately, this is not case in China and Pakistan, in both countries media is controlled by government.

\section{B. Role of Media and Development of Social Structure}

China has one of the most restrictive media systems in the world. The government censors media to maintain its monopoly on power and information. Chinese Communist Party invests a lot of energy and resources to control information as a way to maintain social stability and political control, as well to prevent all potential sources of independent reporting. The comprehensive management consists of four main categories: legal, political, economic, and technological. Legal methods create an environment that is unfriendly to press freedom through restrictive laws 
and regulations, including the structure of official media regulatory bodies. Political instruments include the party's control over the content of news media, official censorship, harassment and imprisonment of journalists. Thirdly, economic methods, which include state ownership of media, bribery on content, and marketization of Chinese news media. Lastly, technology has also been utilized by the Chinese government to counter the recent proliferation of information through the Internet, which includes blocking websites, jamming radio frequencies, and monitoring access to the Internet. According to Zhao (1998) [22], the media is part of a powerful state propaganda tool that is governed by the "Party principle," which comprises of three basic components:

1) News media must reflect the Party's guiding ideology.

2) News media must disseminate the Party's programs, policies, and directives.

3) News media must accept the Party's leadership and subscribe to the Party's organizational principles and press policies.

Chinese government uses media to present only one side of the story, their story in order to remain political and economic control. In Shanxi most of the coal mines are state-owned or co-owned, with an annual production exceeding 300 million metric tonnes, but the province is still considered economically poor. Ten counties around in Shanxi have been designated national-level or county-level poverty-stricken counties. In all of them, coal accounts for $70-75 \%$ of government revenues. Due to coal mine industry in the 2000s, the province was considered to be one of the most polluted areas in China. Safety is one of the issues in province. China's coal industry suffers from this fundamental "safety deficit" because investment in mine safety systems and equipment has lagged behind rises in production.

Pakistan has faced many challenges since its independence, government challenges, democratic and military challenges, natural disasters, earthquake, floods and political challenges. A new democratic government came into power this year (2013). For the first time in history, the previous democratic government transferred its power to newly elected government. There was a great role of media in this process of transferring power.Sindh province has a big disparity among people in different districts. According to the MDGs report (2012) [16] report for Sindh province, Sindh has a dual economy, where progress in urban zones, like Karachi, does not translate to the rest of the province and disparities in the performance of the analyzed indicators in rural areas relative to the urban areas persists.

Pakistan is facing a big challenge of shortage of electricity, and to overcome this challenge, government is trying to attract big firms to come and invest in the coal fields. Government is trying to provide every facility to the coal companies which have been investing their money in coal fields. But the local population of Tharparkar, which has the largest coal fields in the country, is not benefiting from any investment neither by the coal companies nor by the government. People of Tharparkar are living in the same state as they were few decades ago. The state of health has improved but is still very far away even in comparison to other districts of Sindh province. Immunization coverage of
12-23 Months children in Tharparkar is even less than half of total children and it's even worse in rural areas.

Most of the problems affecting child health and the provision of health services to children are the result of the social determinants of health. These include illiteracy, unemployment, gender inequality, and social exclusion, lack of access to safe drinking water, and inadequate sanitation and food insecurity, combined with inadequate funds allocation to health sector. Access to education is also one of biggest challenges in TharParkar district, extremely high instance of non-functional schools pointing to challenges faced by the Government of Sindh in maintaining the physical infrastructure of the education sector. There is lack of effective strategy to address the particular needs of rural women.

In Pakistan, there are not enough laws for coal mining and environmental protection. The first act of environmental protection was set in 1997 after the establishment of ministry of Environment in 1975. This shows that the government has put poor consideration towards the environmental protection. Sindh mining concession rules were approved by the government of Sindh in 2002, and The Thar Coal and Energy Board were established by The Thar Coal and Energy Board bill passed by the provincial assembly of Sindh in 2011 and later on, provincial coal act bill was passed by the provincial assembly of Sindh on $3^{\text {rd }}$ January 2012 as "the Sindh Coal Bill 2012" to provide the regulations and development of coal in the province of Sindh. Pakistan will start producing electricity from coal in few years, but poor laws for environmental protection will create environmental devastation in the near future. Coal mining is dangerous to health and it can cause many diseases including lung diseases in coal mining workers. Coal mining accidents are very common inside coal fields which become more severe when there are no specific laws. Studies should be done on the deposits of coal mining in near future for the production of electricity.

\section{CONCLUSION}

Pollution is main problem for both regions (Shanxi and Sindh), and very few efforts has been done so far to reduce pollution. Safety of workers who are working inside coal mines is another big issue. There is not enough data to prove that coal companies are trying to provide safety measures to their workers. Conditions of health and education are very poor in both Shanxi and Sindh areas compare to rest of the countries, and both governments haven't really done a lot to improve the health and education conditions of local people. Despite of having the biggest coal fields in Shanxi and Sindh, most of the population lives in poverty or on verge of poverty. The poverty rate Sindh is higher than in other provinces of Pakistan, which creates disparity of economy. Role of media is very important in both areas but it is often only one-sided; control of media by government in Shanxi and less coverage on the local population in Sindh are major characteristics of media state in these countries. There are no laws especially in Sindh which describes environmental protection measure, coal mining safety for workers, and coal companies' investment outside of coal fields which are beneficial for the local population. Very few study reports have been done in both areas which show real data which 
explains how much coal fields are affecting the health of local population and causing environmental devastation. Information is the main driver of political change because it provides the masses with the knowledge of their situation. Knowledge can lead to change of regime, both Chinese and Pakistan's government recognizes the vulnerability of their position in the face of truth; therefore, they devote a lot of energy and resources to control information. The power of public pedagogy is vast, the one who controls it, possess the power over people.

\section{REFERENCE}

[1] World Health Organization. (2015). Air quality and health questions and answer. [Online]. Available: http://www.who.int/phe/air_quality_q\&a.pdf

[2] Deaths per TWH by Energy Source. (2011). [Online]. Available: http://nextbigfuture.com/2011/03/deaths-per-twh-by-energy-source. html\#more

[3] Mining Accident. (2015). [Online]. Available: http://en.wikipedia.org/wiki/Mining_accident

[4] J. Burdick and J. A. Sandlin, "Learning, becoming, and the unknowable: Conceptualizations, mechanisms, and process in public PEDAGOGY literature," Curriculum Inquiry, pp. 142-177, 2013.

[5] Shanxi Province: Economic News and Statistics for Shanxi's Economy, In the China Perspective. (2015). [Online]. Available: http://thechinaperspective.com/topics/province/shanxi-province/

[6] Datong Coal Mine Group. (2015). [Online]. Available: http://english.dtcoalmine.com/101992/48718.html

[7] Website of the Sindh Board of Investment. [Online]. Available: http://www.sbi.gos.pk/sindh-economy.php

[8] Sindh Engro Coal Mining Company. [Online]. Available: http://www.engro.com/our-businesses/engro-power-gen-limited/

[9] M. Kenji. (2010). China Bans Reporting on 18 Subjects. [Online]. Available: http://www.asahi.com/english/TKY201003250329.html

[10] China Labor Bulletin. (2008). Bone and blood the price of coal in China. (2015). [Online]. Available: http://www.clb.org.hk/en/files/File/bone_and_blood.pdf

[11] W. Qiu, D. Guo, and T. Shuangguan, "Analysis of eco-environmetal problems in control countermeasures of township coal mines in Shanxi province," Environmental Science and Management, vol. 34, no. 4, pp. 152-156, 2009.

[12] M. Zhang, "In the name of human life: Combing through and reviewing production safety," Workers' Daily, 2002.

[13] International Media Support. (2009). Between radicalization and democratization in an unfolding conflict: Media in Pakistan. [Online]. Available: http://www.ims.dk/files/publications/1491\%20Pakistan.final.web.pdf

[14] Tharcoal Energy Board Website. [Online]. Available: http://www.sindhcoal.gos.pk/coal-fields/thar-coalfield

[15] Oracle Coalfields Is a UK Based Company. [Online]. Available: http://www.oraclecoalfields.com/index.php

[16] UNDP. Report on the Status of Millennium Development Goals, Sindh. (2012). [Online]. Available: http://www.undp.org/content/dam/pakistan/docs/MDGs/UNDP-PKMDG-SindhReport-2012.pdf
[17] World Bank. (2006). Gender gaps in China: facts and figures. [Online]. Available: http://siteresources.worldbank.org/INTEAPREGTOPGENDER/Reso urces/Gender-Gaps-Figures\&Facts.pdf

[18] Greenpeace East Asia. (2013). The health impacts of coal power plants located in Shandong, Shanxi and Inner Mongolia. [Online]. Available: http://www.greenpeace.org/eastasia/publications/reports/climateenergy/2013/health-impacts-coal-shandong/

[19] A. Ren, X. Qiu, L. Jin, J. Ma, Z. Li, L. Zhang, H. Zhu, R. H. Finnell, and T. Zhu, "Association of selected persistent organic pollutants in the placenta with the risk of neural tube defects," in Proc. the National Academy of Sciences, 2011.

[20] H. A. Giroux, "Public pedagogy and the politics of neo-liberalism: Making the political more pedagogical," Policy Futures in Education, vol. 2, no. 3, pp. 494-503, 2004.

[21] Center for Democracy and Governance, The Role of Media in Democracy: A Strategic Approach, Washington, D.C.: U.S. Agency for International Development, 1999.

[22] Y. Zhao, Media, Market, and Democracy in China: Between the Party Line and the Bottom Line, Urbana and Chicago: University of Illinois, 1998

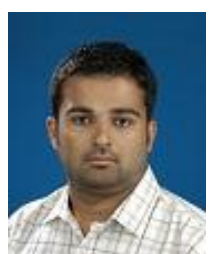

Muhammad Azeem Ashraf was born in Pakistan and He has got his master's degree in the field of comparative education (educational leadership and policy) from Beijing Normal University, Beijing, China.

He started his career as a teacher at Inner Mongolia University for Nationalities, Tongliao, China. His first paper was accepted by International Conference on Social, Education and Sports in ICSES 2014 and first paper was published by International Journal of Research Studies in Language Learning in 2015.

Mr. Ashraf was awarded the best teacher of 2009 year at Inner Mongolia University for Nationalities, Chinese government scholarship for master's degree in 2013 and best graduate student in 2015.

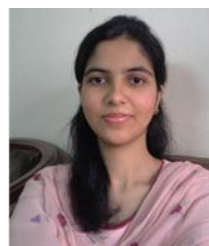

Iqra Ismat was born in Pakistan and She earned his master's degree in 2014 in the field of psychology from Bahauddin Zakariya University Sahiwal Campus.

She has worked in psychology clinic for one year as an internee and started teaching in International Montessori Academy in China.

Mrs. Ismat was awarded the best student under chief-minister of punjab talent program in 2012.

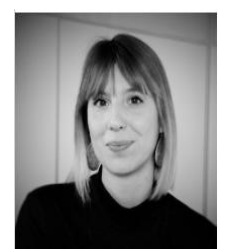

Jelena Milenkovic was born in Serbia and she recieved her master's degree from Beijing Normal University in comparative education (educational leadership and policy).

She started working with thirst for water at China's office in 2014

Ms. Milenkovic was awarder Chinese Government Scholarship in 2013. 